\title{
Does aspirin affect the rate of cataract formation? Cross-sectional results during a randomised double- blind placebo controlled trial to prevent serious vascular events
}

\author{
UK-TIA Study Group ${ }^{\star}$
}

\begin{abstract}
A total of 2435 patients with transient ischaemic attack or minor ischaemic stroke were entered into the UK-TIA aspirin trial and randomised to treatment with aspirin $1200 \mathrm{mg} /$ day, aspirin $300 \mathrm{mg} / \mathrm{day}$, or placebo. At a single point in time during the trial patients were examined ophthalmoscopically for evidence of cataracts. The length of time that each patient had been participating in the trial at the time of ophthalmic examination varied from 1 to 5 years. The prevalence of cataracts was similar in patients allocated aspirin and patients allocated placebo irrespective of the length of time that they had been in the trial. These findings suggest that aspirin taken in a dose of $\mathbf{3 0 0}$ to $1200 \mathrm{mg}$ daily for a few years does not prevent cataracts.
\end{abstract}

Aspirin is a remarkable preparation; it relieves our aches and pains, reduces fever, lowers the risk of serious vascular events in patients with symptomatic cardiac or cerebral ischaemia by about a quarter, ${ }^{1}$ and it is widely available, inexpensive, and relatively non-toxic. Furthermore it has been claimed recently that aspirin may protect against cataract, the world's leading cause of blindness. ${ }^{2-10}$ However aspirin has not been generally accepted as an effective cataract prophylactic because of conflicting data from several other studies. ${ }^{11-16}$ In view of the uncertainty about the effect, if any, of aspirin in preventing blindness, and the implications if it were effective, we took an unusual opportunity to test the hypothesis that aspirin reduces the incidence of cataract formation by examining patients towards the end of the United Kingdom Transient Ischaemic Attack (UK-TIA) aspirin trial. ${ }^{17}$ If aspirin prevents cataract then we would anticipate a divergence of cataract prevalence between those allocated aspirin and those allocated placebo, becoming more marked the longer the patients had been in the trial.

\section{Methods}

Between 25 July 1979 and 8 October 1985 a total of 2435 patients with a recent transient ischaemic attack (TIA) or minor ischaemic stroke entered the UK-TIA aspirin trial and were allocated at random to receive aspirin $600 \mathrm{mg}$ twice daily, aspirin $300 \mathrm{mg}$ once daily, or matching placebo. The trial methods have been published elsewhere. ${ }^{17}$ During 1984/85 surviving patients still attending hospital for follow-up $(n=1889)$ were assessed for evidence of cataract formation; patients were asked whether they had ever been told that they had a cataract and whether they had undergone cataract removal and, if so, when. The patient was then examined by the neurologist using an ophthalmoscope and cataracts were classified as present or absent.

\section{Results}

Table 1 shows the prevalence of cataracts detected ophthalmoscopically in one or both eyes in each of the three treatment groups, the number of cataract extractions performed during the study period up until 1985 among patients in each of the treatment groups, and the number of patients with ophthalmological evidence of cataracts according to the treatment received and the time from randomisation - that is, the duration of treatment. The relative risk of developing ophthalmological evidence of cataracts according to the treatment received and the time from randomisation is illustrated in Figure 1. No significant protective effect is apparent. A separate analysis, excluding those patients who had stopped their trial medication, revealed very similar results.

\section{Discussion}

This study is an example of opportunistic research. After more than 2000 patients with non-disabling cerebral or ocular ischaemia had been randomised to treatment with aspirin or placebo they were examined by their neurologist at a single point in time during follow-up to determine whether they had ophthalmoscopic evidence of cataracts or not.

\section{DIAGNOSIS OF CATARACT}

The neurologists, who were well trained in the 


\begin{tabular}{|c|c|c|c|c|c|c|c|c|}
\hline & \multicolumn{4}{|l|}{ Treatment } & \multicolumn{4}{|l|}{ Treatment } \\
\hline & $\begin{array}{l}\text { Any aspirin } \\
(n=1268)\end{array}$ & $\begin{array}{l}\text { Placebo } \\
(n=621)\end{array}$ & Odds ratio & $\begin{array}{l}95 \% \\
\text { Confidence } \\
\text { interval }\end{array}$ & $\begin{array}{l}\text { Aspirin } \\
300 \mathrm{mg} \\
(n=624)\end{array}$ & $\begin{array}{l}\text { Aspirin } \\
1200 \mathrm{mg} \\
(n=644)\end{array}$ & Odds ratio & $\begin{array}{l}95 \% \\
\text { Confidence } \\
\text { interval }\end{array}$ \\
\hline $\begin{array}{l}\text { Cataract (ophthalmoscop } \\
\text { Yes } \\
\text { No } \\
\text { No eye }\end{array}$ & $\begin{array}{c}162(13 \%) \\
1103 \\
3\end{array}$ & $\begin{array}{c}81(13 \%) \\
539 \\
1\end{array}$ & $1 \cdot 0$ & $(0.8$ to 1.4$)$ & $\begin{array}{c}76(12 \%) \\
547 \\
1\end{array}$ & $\begin{array}{c}86(13 \%) \\
556 \\
2\end{array}$ & 0.9 & $(0.6$ to 1.2$)$ \\
\hline \multirow[t]{2}{*}{$\begin{array}{l}\text { Cataract extraction } \\
\text { (after randomisation) }\end{array}$} & 4 & 3 & & & 0 & 4 & & \\
\hline & $\begin{array}{l}\text { Any aspirin } \\
(n=162)\end{array}$ & $\begin{array}{l}\text { Placebo } \\
(n=81)\end{array}$ & $\begin{array}{l}\chi^{2} \\
(d f=5)\end{array}$ & pvalue & $\begin{array}{l}\text { Aspirin } \\
300 \mathrm{mg} \\
(n=76)\end{array}$ & $\begin{array}{l}\text { Aspirin } \\
1200 \mathrm{mg} \\
(\mathrm{n}=86)\end{array}$ & $\begin{array}{l}\chi_{(d f=5)}^{2} \\
(d f=1\end{array}$ & pvalue \\
\hline $\begin{array}{l}\text { Time from randomisatio } \\
\text { ophthalmoscopic asses } \\
\text { in patients with catarac } \\
\text { (years) } \\
0-1 \\
1-2 \\
2-3 \\
3-4 \\
4-5 \\
5+\end{array}$ & $\begin{array}{l}20 \\
27 \\
27 \\
36 \\
23 \\
29\end{array}$ & $\begin{array}{r}9 \\
11 \\
20 \\
13 \\
13 \\
15\end{array}$ & $3 \cdot 35$ & 0.65 & $\begin{array}{r}9 \\
14 \\
11 \\
20 \\
11 \\
11\end{array}$ & $\begin{array}{l}11 \\
13 \\
16 \\
16 \\
12 \\
18\end{array}$ & $2 \cdot 73$ & $0 \cdot 74$ \\
\hline
\end{tabular}

use of an ophthalmoscope and the interpretation of what was seen, were asked to simply state whether a cataract was present or not in either eye based on the appearance of a definite silhouette of the opacity against the background of the red reflex. Standardised diagnostic criteria were not applied because we were not (and still are not) aware of any internationally accepted diagnostic criteria that could be applied easily in a neurology outpatient clinic. Although there may have been some inaccuracies in the diagnosis of cataract these are unlikely to have biased the results because the examiners were not aware that is, they were 'blind' - of the treatment allocated to the patient. It is likely therefore that any inaccuracies in diagnosis were equally distributed in the aspirin-treated and the placebotreated groups. Furthermore if the prevalence of cataracts (13\%) diagnosed in this population of patients (of mean age 60 (SD 9) years) is compared with the prevalence of cataracts in the 2675 individuals in the Framingham eye study the results were similar. In the Framingham eye study the prevalence of cataracts increased from $4.6 \%$ in those between the ages of 52 and 64 years to $46 \%$ in those between 75 and 85 years. ${ }^{18}$

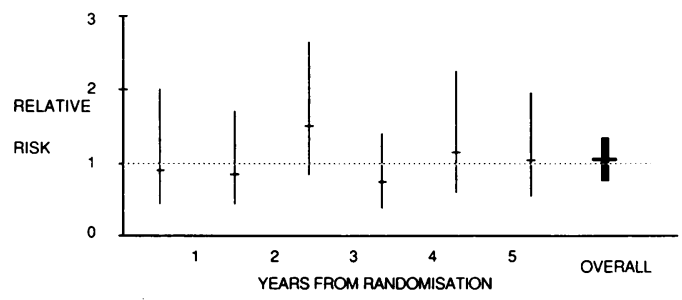

Figure 1 Relative risk (placebo:aspirin) of having ophthalmoscopic evidence of cataracts according to treatmen with placebo or aspirin and the time from randomisation to either placebo or aspirin therapy. If the relative risk is greate than $I \cdot 0$ the prevalence of cataract in patients allocated placebo is greater than in those allocated aspirin. The short horizontal line for each year represents the estimated relative risk and the vertical line the $95 \%$ confidence interval of the estimate. The thick horizontal and vertical lines on the right indicate the estimate and its $95 \%$ confidence interval respectively of the overall relative risk. As all of the $95 \%$ confidence intervals (vertical lines) overlap with a relative risk of $1 \cdot 0$ (dotted line) the result is not statistically significant at the $p=0.05$ level.
FOLLOW-UP

The time interval between randomisation - that is, entry into the study - and the ophthalmological examination for cataracts varied among the patients from less than 1 to more than 5 years. It is not known whether any cataracts had developed before or after treatment was commenced with aspirin or placebo. However the process of randomisation protects against systematic bias in treatment allocation.

RESULTS

If aspirin has a protective effect on cataract formation it would be expected, in a study of this kind, that the relative risk of having a cataract would be approximately one within the first year of randomisation and, as the time interval from randomisation to assessment increased, the prevalence of cataract formation in the placebo group would gradually increase compared with the aspirin-treated group. This was not the case; there was no significant change in the relative risk over the first 5 years of treatment and no evidence to suggest a time-dependent effect.

CONCLUSION

The limitations of this study are not that the diagnosis of cataract was based upon a relatively crude method (an ophthalmoscope) but that the primary measure of outcome (cataract formation) was assessed at a single point in time only and that the number of patients with cataracts was fairly small, leading to imprecise estimates of relative risk with fairly wide confidence intervals and hence the possibility of a 'false negative' result. Nevertheless the results do not support the hypothesis that $300-1200 \mathrm{mg}$ daily aspirin, taken for a few years, is an effective cataract prophylactic.

This paper was prepared by Dr Graeme Hankey, Dr Susan Richards and Professor Charles Warlow.

The UK-TIA aspirin trial was supported by a grant from the Medical Research Council and the European Aspirin Foundatior Medical Research Council and the European Aspirin Foundation
and Dr Hankey received a grant from the Chest Heart and Strr'ke and Dr Hankey received a grant from the Chest Heart and Strc, $k$ e
Association. We are grateful for helpful comments on the $m^{2}$ anuscript by Dr P Sandercock, Mr R Peto and Ms B Farrell. 
1 Antiplatelet Trialists' Collaboration. Secondary prevention of vascular disease by prolonged antiplatelet treatment. $B M$ 1988; 296: 320-31.

2 Cotlier E. Rheumatoid arthritis and cataract surgery. Int Ophthalmol 1980; 2: 127-9.

Cotlier E, Sharma YR. Aspirin and senile cataracts in rheumatoid arthritis. Lancet 1981 ; i: 338-9.

4 Cotlier E. Senile cataracts: evidence of acceleration by diabetes and deceleration by salicylate. Can $\mathcal{F}$ Ophthalmol 1981; 16 : 113-8.

5 Cotlier E, Sharma YR, Niven T, Brescia M. Distribution of salicylate in lens and intraocular fluids and its effect in cataract formation. Am F Med 1983; 74: 83-90.

6 Crompton $\mathrm{M}$, Rixon $\mathrm{KC}$, Harding JJ. Aspirin prevents carbamylation of soluble lens proteins and prevents cyanateinduced phase separation opacities in vitro: a possible mechanism by which aspirin could prevent cataract. Exp Eye Res 1985; 40: 297-311.

7 Rao GN, Lardis MP, Cotlier E. Acetylation of lens cystallins: a possible mechanism by which aspirin could preven cataract formation. Biochem Biophys Res Comm 1985; 128 : $1125-32$.

8 Van Heyningen $\mathbf{R}$, Harding JJ. Do aspirin-like analgesics protect against cataract? A case-control study. Lancet 1986; i: $1111-3$.

9 Harding JJ, Van Heyningen R. Drugs, including alcohol, that act as risk factors for cataract, and possible protection gainst cataract by aspirin-like analgesics and cyclopenthiazide. Brf Ophthalmol 1988; 72: 809-14.
10 Swamy MS, Abraham EC. Inhibition of lens crystallin glycation and high molecular weight aggregate formation by aspirin in vitro and in vivo. Invest Ophthalmol Vis Sci 1989 30: $1120-6$

11 Seigel D, Sperduto RD, Ferris FL III. Aspirin and cataracts. Ophthalmology 1982; 89: 47-8A

12 Seigel D, Sperduto RD, Ferris F. Is ASA therapy for cataract justified? Can 7 Ophthalmol 1982; 1: 135-6.

13 Kewitz H, Nitz M, Gaus V. Aspirin and cataract. Lancet 1986; ii: 689.

14 West SK, Munoz BE, Newland HS, Emmett EA, Taylor HR. Lack of evidence for aspirin use and prevention of cataracts. Arch Ophthalmol 1987; 105: 1229-31.

15 Peto R, Gray R, Collins R, et al. A randomised trial of the effects of prophylactic daily aspirin among male British doctors. BMF 1988; 296: 313-6.

16 Paganini-Hill A, Chao A, Ross RK, Henderson BE. Aspirin use and chronic diseases: a cohort study of the elderly. $B M \mathcal{F}$ 1989; 299: 1247-50.

17 UK-TIA Study Group. United Kingdom transient ischaemic attack (UK-TIA) aspirin trial: interim results. BMF 1988; 296: $316-20$.

18 Kini MM, Leiowitz HM, Colton T, Nickerson RJ, Ganley J, Dawber TR. Prevalence of senile cataract, diabetic retinopathy, senile macular degeneration, and open-angle glaucoma in the Framingham eye study. Am 7 Ophthalmol 1978; 85: 28-34.

19 Gardner MJ, Altman DG, eds. In: Statistics with confidence. Belfast, Universities Press. BMF, 1989.

\section{FIFTY YEARS AGO}

\section{Tobacco Amblyopia}

In hospital practice, in which tobacco amblyopia is common, the patients do not come from the section of the population in which hard drinking by both sexes, often supported by cheap alcohol, is frequent. These people come to the medical and surgical outpatient departments and exhibit the clinical picture of chronic alcoholism; they do not come to the eye department complaining of impaired vision. If alcohol were an important factor toxic amblyopia would be much more common in women than it is. Tobacco amblyopes are frequently moderate or light drinkers and are often teetotallers.

$$
\text { Brf Ophthalmol 1942; 26: } 43 .
$$

